\title{
Jornada de articulación entre docentes de Matemática de Colegios Secundarios y de Universidad: una experiencia en la Facultad de Ingeniería de la Universidad Nacional de La Plata, Argentina
}

Meeting of articulation between teachers of Mathematics of High Schools and University: an experience in the Faculty of Engineering of the National University of La Plata, Argentina.

\author{
Rossana Di Domenicantonio \\ rossanadido@ing.unlp.edu.ar \\ Facultad de Ingeniería, UNLP \\ La Plata, Argentina
}

\author{
Mabel García \\ mabel.garcia@ing.unlp.edu.ar \\ Facultad de Ingeniería, UNLP \\ La Plata, Argentina
}

\author{
Laura Langoni \\ laura.langoni@ing.unlp.edu.ar \\ Facultad de Ingeniería, UNLP \\ La Plata, Argentina
}

Resumen: En este trabajo se relata una experiencia de articulación entre docentes de Matemática de colegios secundarios y de la universidad, con la finalidad de colaborar con la adaptación de los alumnos que pasan de un nivel al otro. La misma se desarrolló en tres jornadas en la Facultad de Ingeniería (FI) de la Universidad Nacional de La Plata (UNLP), Argentina. En los encuentros se difundió la forma de trabajo en las aulas de Matemática de la FI. Los docentes participantes intercambiaron opiniones acerca de las fortalezas y debilidades que presentan los alumnos que están en el tránsito del secundario a la universidad. Se generó un interesante debate con las realidades expresadas, lo que resultó enriquecedor del proceso de enseñanza aprendizaje en ambos niveles. Además, se realizó una encuesta a los docentes que participaron de las jornadas sobre estos aspectos, presentándose aquí los resultados y conclusiones.

Palabras Clave: articulación, matemática, docentes, colegio secundario, universidad.

Abstract: In this work, an articulation experience between secondary school and university mathematics teachers is reported, in order to collaborate with the adaptation of students who pass from one level to the other. It was developed in three days at the Faculty of Engineering (FI) of the National University of La Plata (UNLP), Argentina. In the meetings, the way of working in the Mathematics classrooms of the FI was disseminated. The participating teachers exchanged opinions about the strengths and weaknesses of students who are in the transition from high school to university. An interesting debate was generated with the realities expressed, which was enriching in the teaching-learning process at both levels. In addition, a survey was carried out among the teachers who participated in the conferences on these aspects, presenting the results and conclusions here.

Keywords: articulation, mathematics, teachers, high school, university. 


\section{Introducción}

El Programa NEXOS de Articulación Educativa Universidad - Escuela Secundaria, dependiente del Ministerio de Educación de la Presidencia de la Nación Argentina, es un proyecto que fue implementado en la Facultad de Ingeniería de la UNLP desde la convocatoria 2017. Este programa promueve espacios y acciones de intercambios entre la escuela secundaria y la universidad. Además, favorece la continuidad del estudio secundario y el ingreso a la educación superior. La articulación entre estos dos niveles educativos se configura como uno de los ejes centrales del programa para construir mecanismos que permitan alcanzar un diagnóstico compartido y un plan de trabajo, tanto de las instituciones participantes como de los actores involucrados. En este contexto, la FI presentó la propuesta de "mesas de trabajo con docentes de matemática del ciclo superior del colegio secundario", organizando y difundiendo estas jornadas con docentes de los dos niveles educativos. La FI mantiene una política de articulación con el secundario a través de un proyecto de extensión (Matemática-FI) especialmente pensado para este fin, con charlas de difusión de carreras en las escuelas y con eventos públicos como el Festival de Matemática, donde se invitó a los alumnos de los colegios de la región. Sin embargo, las jornadas que se relatan en este trabajo son las primeras que se realizan en la Facultad con el fin de articular con docentes del secundario. Por ser la primera vez, a criterio de los organizadores, se alcanzó un número de asistentes muy satisfactorio.

Con esta propuesta se pretendieron alcanzar los siguientes objetivos generales:

- Articular con docentes de Matemática del colegio secundario.

- Difundir la forma de trabajo en las aulas de Matemática de la FI donde se trabaja con modalidad de aula taller.

- Intercambiar distintas perspectivas entre los docentes de los dos niveles educativos acerca de las fortalezas y debilidades que presentan los alumnos que se encuentran en el tránsito del secundario a la universidad.

- Hacer un recorrido sobre los temas curriculares del ciclo superior del secundario que, por diversos motivos, no hubieran sido estudiados o profundizados por los alumnos pero que en el nivel universitario se consideran como conocimientos previos necesarios.

La difusión de la Jornada fue realizada principalmente por la FI y tuvo el apoyo de la Dirección General de Escuelas de la Provincia de Buenos Aires. Dado que el número de inscritos fue mayor al esperado y con la finalidad de que las actividades se desarrollaran con modalidad de taller, se decidió llevar a cabo tres encuentros con igual programa.

\section{Fundamentación}

La Dirección de Currícula del Gobierno de la Ciudad Autónoma de Buenos Aires define la articulación como la unión o enlace entre partes. Estas partes son distintas entre sí pero a la vez forman parte de un todo (Dirección de Currícula, 2000). De acuerdo con Luchetti, "La articulación es una estrategia para favorecer la continuidad de los aprendizajes, la gradualidad del proceso y el pasaje feliz, mórbido, fluido, seguro y no traumático interniveles" (Luchetti, 2005, p.12). La importancia de la articulación entre la universidad y la escuela secundaria remite a las palabras del Dr. Arq. Fernando Tauber, quien es actualmente presidente de la Universidad Nacional de La Plata:

La Universidad tuvo una distancia marcada con el secundario, todavía hoy sobreviven discursos que plantean 'la condición en la que vienen los chicos', pero también empieza a construirse muy sólidamente una comprensión de que la educación del individuo es a lo largo de toda la vida, de que no hay un ciclo separado del otro, que somos todos parte del problema y de la solución y que a todos nos corresponde una parte de esa responsabilidad 
y que amalgamar y volver natural el paso de una etapa a la otra es lo que le da oportunidades al proceso para que efectivamente pueda tener una solución positiva. (Tauber, 2010)

Según Aguerrondo (2009) los mayores niveles de fracaso escolar se presentan en los cambios de nivel, ya sea de la escuela primaria al colegio secundario o de éste a la universidad. La brecha entre los dos niveles educativos hace que el tránsito sea dificultoso, por lo que la articulación entre ellos debe ser considerada herramienta fundamental para permitir una continuidad pedagógica efectiva, que redefina los procesos educativos para graduar el pasaje de un ámbito al otro (Belinche et al, 2014). Es de destacar que "la articulación implica no solo vínculos y conexiones entre los contenidos, sino también entre las concepciones de enseñanza y de aprendizaje; con la idea de sujeto que le subyace y con acuerdos acerca de qué significa saber" (De Moreno, 2015, p.6). Desde la mirada de docentes de la FI "La consecuencia lógica de la articulación entre niveles es la continuidad educativa, de modo que se genera una secuencia lógica de adquisición de saberes, contenidos conceptuales, procedimientos y técnicas de estudio" (Vargas et al, 2017).

En este sentido se pensaron e implementaron diversas estrategias en la FI con el fin de minimizar el salto entre los niveles educativos y, de esta manera, favorecer en alguna medida la articulación entre ambos niveles y el tránsito de los alumnos. Una de esas estrategias fueron las Jornadas con Docentes de Matemática de Colegios Secundarios.

Los encuentros fueron planificados y desarrollados adoptando características del aula taller, del mismo modo que trabajan los alumnos en las clases de matemática de la FI. Concebimos al aula taller, en concordancia con Ander Egg (1991, p.12), "como una forma de enseñar y aprender mediante la realización de algo que se lleva a cabo conjuntamente. Es un aprender haciendo en grupo". Este tipo de metodología lleva intrínseca supuestos y principios que lo caracterizan. Algunos de ellos son el aprender haciendo, la metodología participativa, la pregunta como modo de cuestionar, la relación entre la cantidad de docentes y la cantidad de alumnos y el trabajo grupal, entre otros. Castelló et al. (2012) y Altamirano et al. (2015), entre otros autores, afirman que, en general, los alumnos de nivel secundario y en particular los alumnos que ingresan a las distintas carreras técnicas presentan una forma de estudio más ligada a lo memorístico y repetitivo. De acuerdo con García (2017, p. 3), la metodología de aula-taller implementada en los cursos de Matemática de la FI "les exige a los estudiantes una participación activa en la construcción de su propio conocimiento, ser crítico de sus producciones y de las de sus pares y debiendo, además, fundamentar sus razonamientos".

Durante las jornadas tanto los docentes anfitriones como los invitados, fueron conformando un espacio de trabajo conjunto que se fue enriqueciendo a medida que los docentes invitados se fueron involucrando con la propuesta. Se buscó mostrar a los docentes una manera diferente de trabajo en el aula, en un ambiente distendido y con materiales especialmente diseñados para tal fin. Desde este punto de vista, las jornadas de articulación resultan ser una capacitación docente, en el sentido de incorporar herramientas didácticas que resulten útiles para los alumnos próximos a ingresar a la universidad. Según Camargo (2004, p.81), "la formación permanente del docente debe entenderse como un proceso de actualización que le posibilita realizar su práctica pedagógica y profesional de una manera significativa, pertinente y adecuada a los contextos sociales en que se inscribe y a las poblaciones que atiende." Espinosa (2012, p.40) define la capacitación como la "acción destinada a incrementar las aptitudes y los conocimientos del trabajador con el propósito de prepararlo para desempeñar eficientemente una unidad de trabajo específico e impersonal". Según Blanco Hernández (2008), la capacitación debe considerarse un proceso de aprendizaje continuo, que permita mejorar el desempeño de las personas involucradas en la misma. Más específicamente en el ámbito docente, la capacitación debe ser diseñada a partir del diagnóstico de necesidades para permitir solucionar problemas actuales y futuros. El profesor debe apoyar a sus alumnos a construir el conocimiento y guiarlos para que crezcan como personas y sean críticos de sí mismos y de su entorno, por lo que una buena capacitación docente debería incluir competencias congruentes con esas tareas (Rodríguez Vite, 2017). 


\section{Metodología}

Se presenta aquí un reporte sobre la experiencia de tres Jornadas de capacitación docente. Para esto, se hizo un estudio cualitativo de tipo descriptivo con algunos análisis cuantitativos. Según Ruiz Olabuénaga (2012, p.12), "el innegable éxito que los métodos cualitativos están encontrando entre los investigadores contemporáneos es más una reconquista oportuna que un descubrimiento inesperado". Con relación a este tipo de investigación, Díaz Herrera (2018, p.124) afirma que "el estudio cualitativo apela a una observación próxima y detallada del sujeto en su propio contexto, para lograr aproximarse lo más posible a la significación de los fenómenos".

Las jornadas tuvieron lugar en distintos días en los meses de agosto y septiembre del año 2019, desarrollándose en dependencias de la FI. Participaron 112 docentes de materias de Matemática de escuelas secundarias privadas y públicas (provinciales, de la UNLP y/o técnicas) de la ciudad de La Plata y localidades cercanas. En la Tabla 1 se puede observar el detalle de la cantidad de docentes y colegios participantes en cada una de las jornadas.

Tabla 1: Cantidad de asistentes y colegios representados en cada una de las jornadas.

\begin{tabular}{ccc}
\hline Jornada & Docentes & Colegios \\
\hline $1^{\circ}$ & 46 & 32 \\
$2^{\circ}$ & 36 & 29 \\
$3^{\circ}$ & 30 & 26 \\
\hline
\end{tabular}

Los docentes participantes se habían inscrito mediante un formulario en línea para poder participar (Anexo A.1). Los colegios que de alguna manera ya se encontraban trabajando con la Facultad fueron invitados directamente, mientras que otros fueron convocados a través de la Dirección General de Escuelas.

Las actividades fueron coordinadas, dirigidas y organizadas por docentes de materias de Matemática de los primeros años de las carreras de Ingeniería, mayormente de la cátedra de ingreso de esta casa de estudios.

Para el desarrollo de este trabajo, se revisó bibliografía específica, se diseñaron las actividades para implementar en las jornadas, se analizaron las respuestas y las opiniones de los docentes sobre las mismas y se observó el desempeño colaborativo que tuvieron estos en los distintos grupos que se armaron. Además, se implementó una encuesta dirigida a los docentes que participaron de la experiencia y se analizaron sus resultados.

Cada Jornada se desarrolló en dos bloques de una hora y media de duración, separados por un intervalo de 30 minutos. En el primer bloque se dio la bienvenida, tras lo cual se pidió a los docentes que se organizaran en grupos y se les entregó una actividad impresa para trabajar en conjunto. Se dejó libertad a los docentes para la formación de los grupos, señalando únicamente que debían contener de cuatro a seis integrantes. No asistieron más de tres docentes de cada colegio, lo que aseguraba que en cada grupo hubiera representantes de más de un establecimiento. Debían analizar el enunciado de un problema que habitualmente se les da a los alumnos ingresantes a la Facultad y que promueve la metodología de aula taller en los cursos. La actividad realizada, "El túnel y el camión" (Figura 1), consiste en un problema de aplicación a un caso real, donde se deben utilizar nociones básicas de cónicas, en particular, de elipse. Para la resolución de la situación problemática se necesita la identificación gráfica de la elipse y el conocimiento tanto de su ecuación como de algunos de sus elementos.

Si bien cónicas es un tema curricular de la escuela media, los alumnos suelen llegar a las clases de Matemática de la FI aduciendo que no lo han visto anteriormente, por lo que esta actividad, y otras similares, les pueden generar dificultades. 


\section{EL TÚNEL Y EL CAMIÓN}

Sobre un camino de mano única se construyó un túnel que atraviesa una montaña. El techo del túnel tiene la forma de un semi arco elíptico, con un eje mayor horizontal de $15 \mathrm{~m}$ y una altura, en el centro, de $3 \mathrm{~m}$.
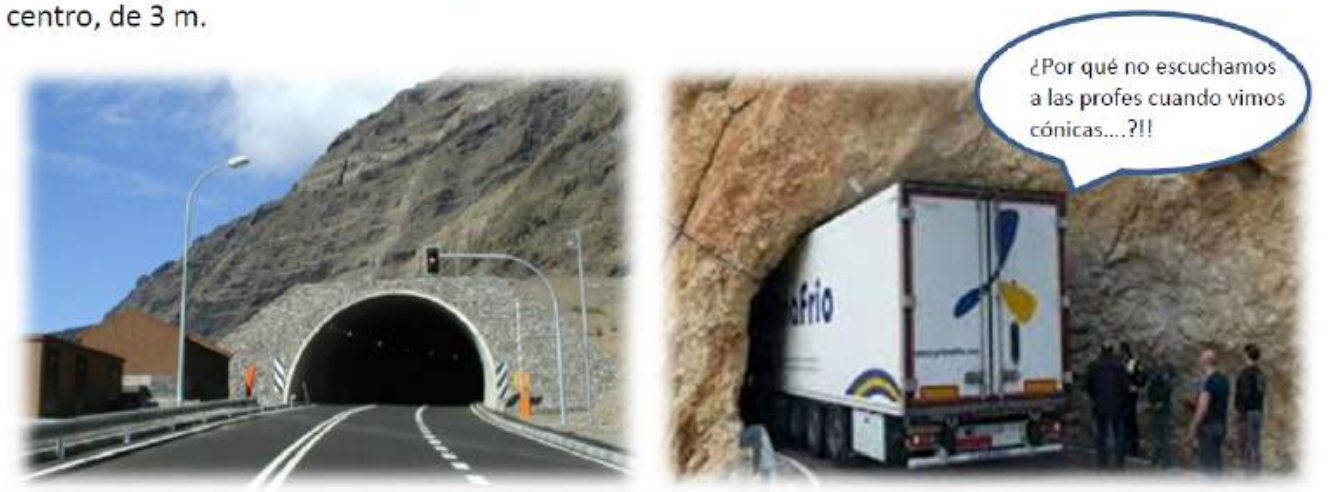

a) Esquematicen la entrada del túnel en un sistema de ejes cartesianos, haciendo coincidir el centro del camino con el origen de coordenadas.

b) Identifiquen y señalen las coordenadas de los puntos conocidos.

c) Determinen la ecuación que representa al arco semielíptico del techo del túnel.

d) Supongan que están conduciendo un camión que tiene un ancho de 2,4 m y una altura de 2,8 $m$ y deciden tomar ese camino. Agreguen al gráfico anterior un esquema del camión en la ubicación más conveniente para que pueda pasar.

e) ¿Podrán atravesar el túnel? Justifiquen analíticamente.

Figura 1: Enunciado de la actividad "El Túnel y el camión". Fuente: Enunciado de elaboración propia y fotos de Maxi Hormeño.

Durante el tiempo en que los docentes invitados analizaban la actividad recibida, los anfitriones recorrían los distintos grupos de trabajo (Figura 2) con la finalidad de colaborar en caso de que fuera requerido, tal como se hace habitualmente en las aulas de clase de Matemática de la Facultad.

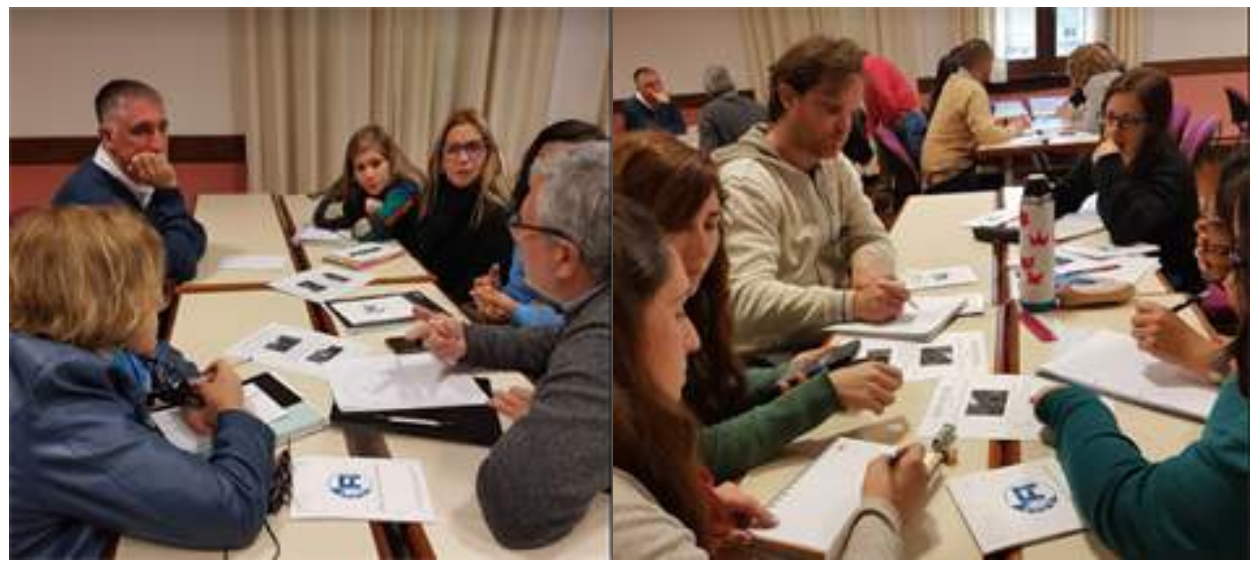

Figura 2: Grupo de docentes en mesas de trabajo. Fuente: Elaboración propia.

La tarea de los participantes no era resolver la actividad sino analizar el enunciado para debatir, junto a los pares de su mesa, sobre los inconvenientes que hubieran podido encontrar sus alumnos al resolver la actividad y las preguntas y respuestas que podrían haberle realizado a ellos como docentes del aula. De acuerdo con Walker (2012, p.51), "la indagación de las representaciones que los docentes tienen respecto de sus estudiantes permite acercarnos a las concepciones que sustentan las prácticas de enseñanza y que pueden estar favoreciendo $u$ obstaculizando los procesos de aprendizaje de los alumnos".

Finalizada esta tarea, se les propuso a los participantes que completaran un cuestionario, de manera 
individual, en referencia a la actividad con la que habían trabajado (Anexo A.2) y a sus percepciones y experiencias en sus propios cursos (Anexo A.3); tras lo cual tuvo lugar un intervalo donde se siguieron compartiendo vivencias y opiniones aunque en pequeños grupos y de manera más informal.

En el $2^{\underline{o}}$ bloque, por medio de una presentación, se detalló la estructura de las materias de Matemática de los primeros años de las carreras de la FI. Además, se explicó a los presentes cuáles fueron los orígenes de la implementación de la metodología de aula taller en nuestros cursos. Luego, y con el apoyo de un video, se mostró la manera actual de trabajo en el aula, describiendo y observando los distintos momentos de una clase.

Se habló acerca de los recursos didácticos que se utilizan en las aulas, tales como: guía de clase teóricopráctica, aula extendida en el entorno virtual de enseñanza y aprendizaje Moodle $u$ otros, ejercicios y actividades complementarias (Anexo A.4). Las guías teórico-prácticas de las materias iniciales de matemática de la FI son elaboradas por coordinadores y docentes de las materias y promueven el trabajo colaborativo de los alumnos, abordando todos los contenidos de cada asignatura. Con relación al aula extendida, se utilizan distintos recursos digitales como foros de preguntas y respuestas, cuestionarios en línea, mini videos, entre otros. El aula extendida permite a los alumnos estar en contacto con los docentes para facilitar la comunicación y consultar dudas en tiempos y espacios que no coincidan con los horarios de clase. También se proponen, a través de la misma, ejercitaciones y actividades adicionales. Se denomina aula extendida, según González et al. (2012), a una propuesta pedagógicotecnológica donde la acción del docente excede o se extiende fuera de los medios tradicionales de su clase con la ayuda de diversos soportes tecnológicos. Los mismos autores afirman:

El uso de la tecnología digital extiende las posibilidades de la clase en términos de búsqueda de recursos, interacción con el profesor y los demás alumnos y la preparación de los exámenes. Sería como una clase presencial extendida a través de las tecnologías. (González et al, 2012, p.16)

Con respecto a la evaluación en estos cursos, se explicó que es continua, considerando la actitud en clase, el trabajo en grupo, las producciones individuales y grupales y los exámenes parciales. Por último, se mostraron a los docentes los resultados cuantitativos de una encuesta que se hizo a los alumnos respecto a su percepción sobre la forma de trabajar en el aula (Anexo A.5).

Finalizada la presentación, hubo un tiempo de preguntas y respuestas con los docentes que se vio enriquecido con un intercambio de opiniones y descripciones sobre la forma de trabajo en las aulas del colegio secundario como así también detalles de algunos temas curriculares (Figura 3).

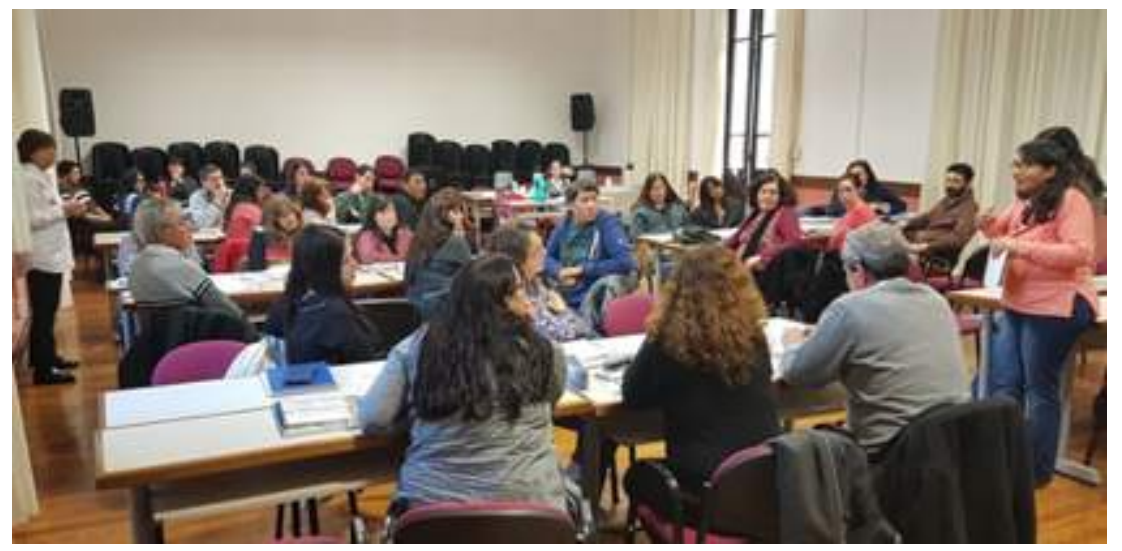

Figura 3: Intercambio entre los docentes invitados y los anfitriones. Fuente: Elaboración propia. 


\section{Resultados}

Los docentes invitados respondieron un cuestionario al finalizar el primer bloque del encuentro. En general, hubo muy buena predisposición de su parte, aunque algunos de ellos no lo completaron en su totalidad.

El cuestionario constaba de tres partes: la primera sobre datos personales de los encuestados (dos preguntas); la segunda donde se consultó sobre la actividad de "El Túnel y el camión" (siete preguntas); y la tercera sobre la percepción que ellos tenían acerca de sus propios alumnos (dos preguntas), como serán detalladas y analizadas a continuación.

La primera parte del cuestionario tenía por finalidad conocer datos personales de los docentes participantes como ser de qué institución provenían los docentes, así como también en qué años de la escuela secundaria desarrollaban su actividad. Se puede destacar que la mayor parte de los docentes invitados (69\%) provenían de escuelas secundarias privadas (Figura 4). La intervención de la Dirección Provincial de Educación de Gestión Privada (DIPREGEP) en la divulgación de las jornadas pudo haber influido en esta condición. El 89\% de los asistentes realiza su tarea docente, en su totalidad o parcialmente, en los últimos tres años de la escuela secundaria. Este porcentaje se debe probablemente a que las direcciones de los establecimientos invitados consideraron que el tema de articulación, a tratar en las jornadas, no sería tan bien aprovechado por docentes de los primeros años.

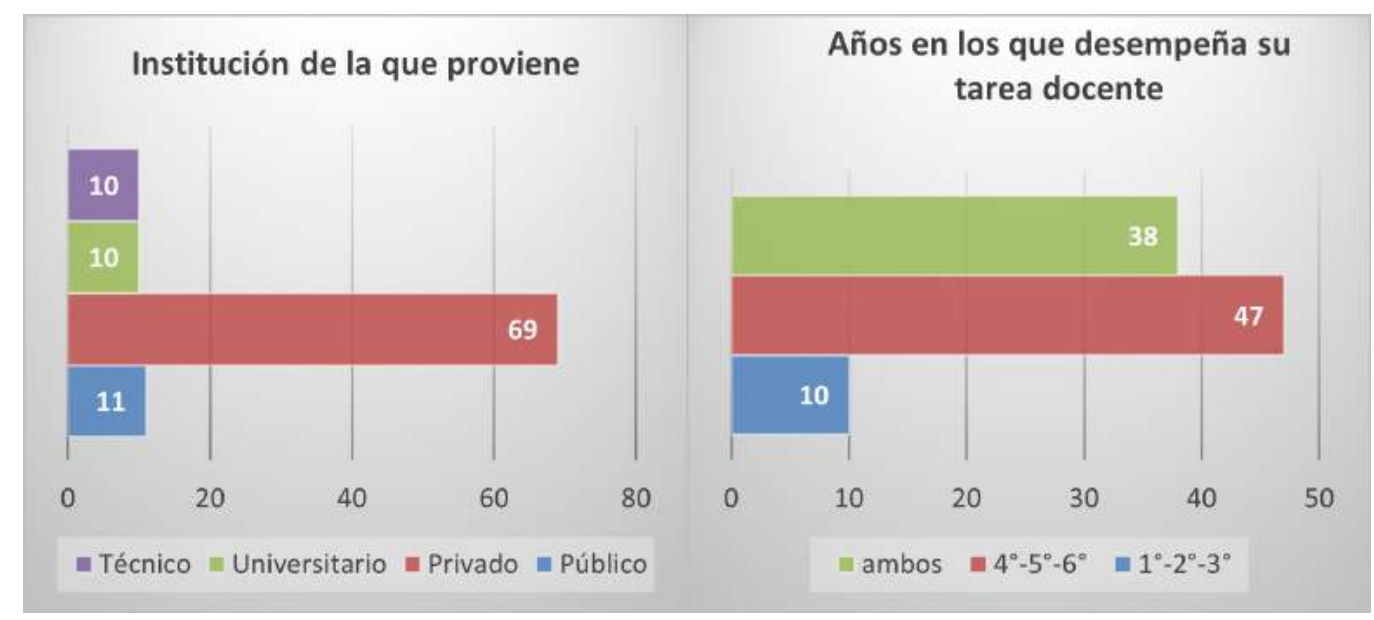

Figura 4: Resultados sobre el tipo de institución y los años en que desarrollan la tarea docente. Fuente: Elaboración propia.

La segunda parte del cuestionario continuaba con una serie de siete preguntas referidas a la apreciación de los docentes sobre la actividad "El Túnel y el Camión", sobre cómo la llevarían a cabo en sus aulas y cómo creerían que iban a actuar sus alumnos ante una propuesta como esa en el aula. La pregunta 1 se refería al momento en que les propondrían esta actividad a sus alumnos y se observó que las opiniones de los docentes fueron distribuidas en partes similares entre las opciones disponibles (Figura 5).

Se puede señalar que se observó una leve tendencia a considerar la presentación de la actividad antes o durante el desarrollo del tema en cuestión frente a hacerlo como cierre. Algunos docentes seleccionaron la opción "Otros"; entre sus argumentos se pueden destacar que no se estaba dictando el tema cónicas en la escuela, por lo que no podría darse esa actividad a los estudiantes, o bien que los tiempos de clase dejaban poca posibilidad al desarrollo de actividades en grupo con un cierre mediante una puesta en común.

El 86\% de los docentes afirmó que sus alumnos podrían trabajar en grupos (Figura 6). Con relación a si los alumnos eran capaces de resolver la actividad sin inconvenientes la gran mayoría de los encuestados manifestó que los estudiantes necesitarían ayuda para poder resolverla (Figura 6). Un resultado 


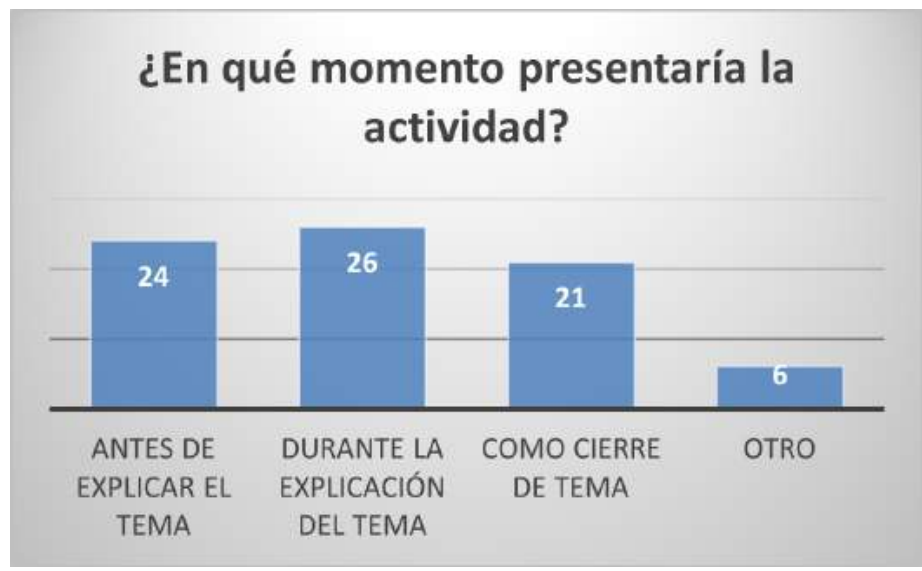

Figura 5: Resultados de la pregunta 1. Fuente: Elaboración propia.

similar se observó cuando se les consultó si los alumnos hubiesen podido modelizar la actividad si la misma no hubiera estado pautada (Figura 6).

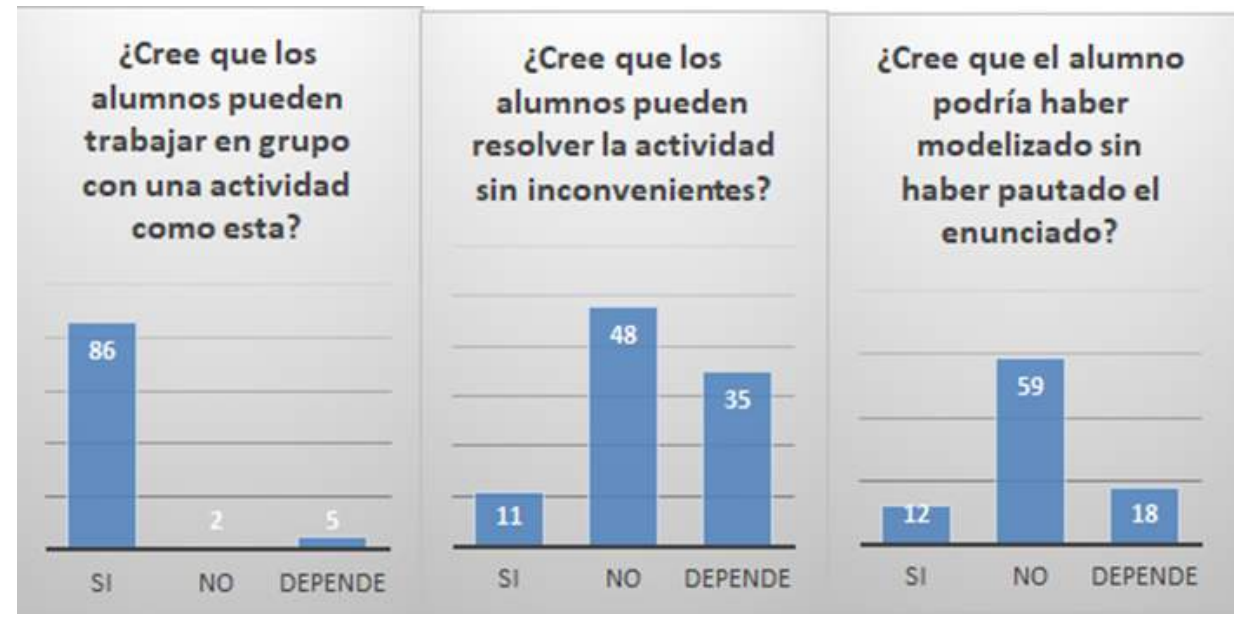

Figura 6: Resultados de las preguntas 2, 3 y 4 del cuestionario. Fuente: Elaboración propia.

Entre los argumentos esgrimidos por quienes respondieron "Depende" al consultarles por los inconvenientes que pudiesen haber tenido los alumnos, podemos destacar la vinculación de la capacidad para resolver la actividad con el momento en el cual se elija presentarla (antes, durante o después de ver el tema cónicas). También se señaló la asociación con la asistencia del docente durante el proceso de resolución. Este argumento fue también señalado al referirse a la modelización. Si la percepción de los docentes concuerda con las competencias con que llegan los alumnos a estudiar carreras de Ingeniería, se tendrían que implementar nuevas estrategias tendientes a mejorar estas habilidades.

En las últimas tres preguntas de la segunda parte de la encuesta los docentes podían seleccionar más de una opción si así lo consideraban. Cuando se consultó sobre qué inconvenientes podían presentar los alumnos al momento de resolver la actividad, la mayoría se inclinó por "Modelizar el problema", siguiendo a esta opción "Interpretación del problema" y "Conocimiento del concepto elipse" (Figura 7 ). El resto de las opciones fueron seleccionadas en cantidades similares o muy poco seleccionadas. Esta pregunta motivó un intercambio de información sobre los contenidos que en la universidad se consideran conocimientos previos y que en la realidad no siempre los alumnos poseen.

Se consultó a los docentes sobre cuándo era más conveniente su intervención durante la actividad; la opción más seleccionada fue "Cuando el alumno lo necesite o requiera" (Figura 8). En segundo lugar, se seleccionó la opción que proponía que la intervención fuera en todo momento y luego la opción referida al cierre de tema y debate. 


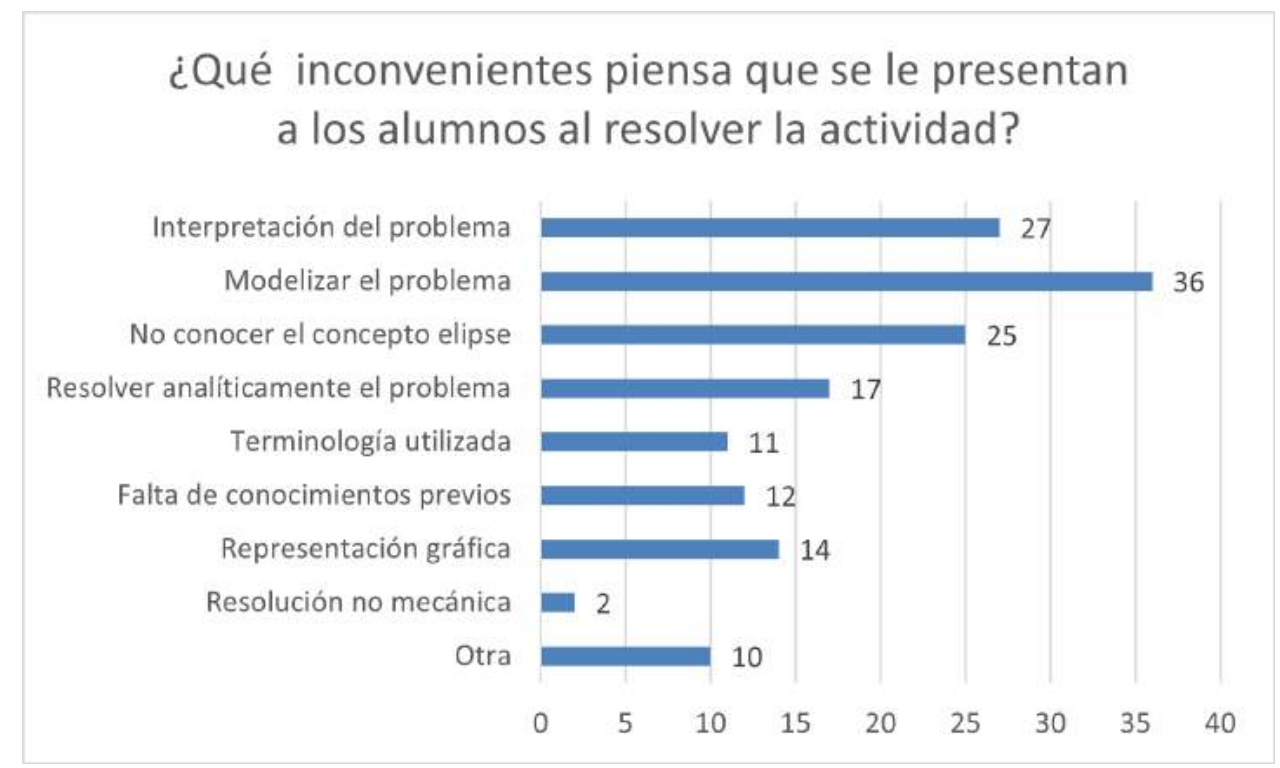

Figura 7: Resultados de la pregunta 5 del cuestionario. Fuente: Elaboración propia.

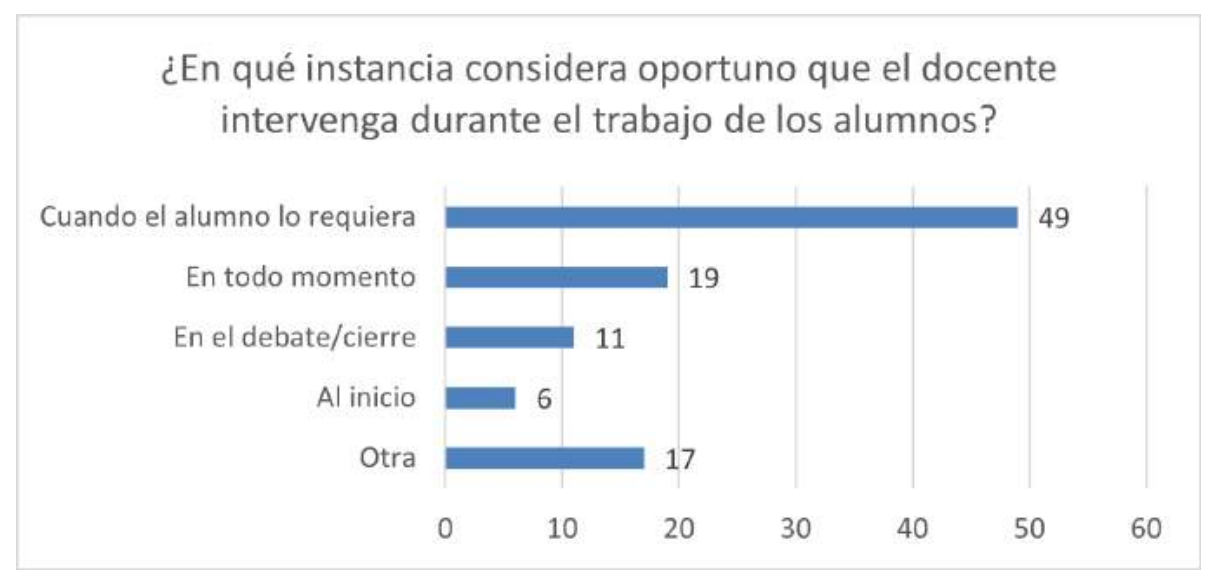

Figura 8: Resultados de la pregunta 6 del cuestionario. Fuente: Elaboración propia.

Respecto a cómo cerrarían la actividad en sus aulas, podemos destacar que mayoritariamente los docentes indicaron que la forma de cerrar la actividad sería mediante una puesta en común con trabajo en pizarrón y confrontación de ideas (Figura 9). Aquí algunos participantes proponían hacer pasar alumnos al pizarrón mientras que otros preferían que fuera el docente quien concluyera con la resolución detallada del problema.

La tercera parte del cuestionario constaba de dos preguntas: una referida a la percepción de los docentes sobre las dificultades que presentan sus alumnos y la otra sobre los aspectos que valorizan de ellos. En ambas era posible elegir más de una opción. En la primera las opciones más seleccionadas fueron las referidas a la falta de motivación y buenos hábitos de estudio (Figura 10). En segundo lugar, señalaron las referidas a la poca paciencia, reflexión e interpretación lectora, así como a la falta de conocimientos previos. Los docentes manifestaron percibir que los adolescentes son bastante reacios al estudio de la matemática salvo al proponérseles algún problema motivador. En este sentido valorizaron la propuesta presentada y se sintieron motivados para proponerla a sus alumnos.

$\mathrm{Al}$ responder sobre los aspectos que valorizaban de los alumnos, la mayor parte de los encuestados optaron por señalar que se animaban a expresar sus ideas y que aprovechaban el uso de las Tics (Figura 11). En menor medida se seleccionaron las opciones referidas a la buena predisposición de los alumnos cuando les gusta la temática y su motivación ante desafíos. 


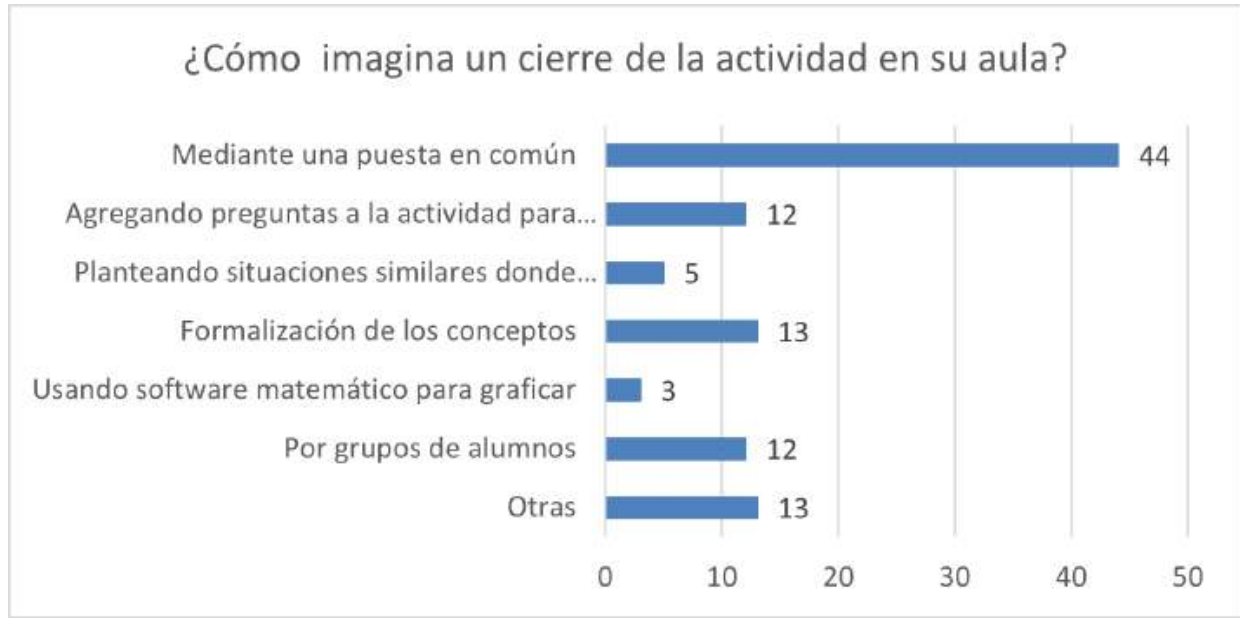

Figura 9: Resultados de la pregunta 7 del cuestionario. Fuente: Elaboración propia.

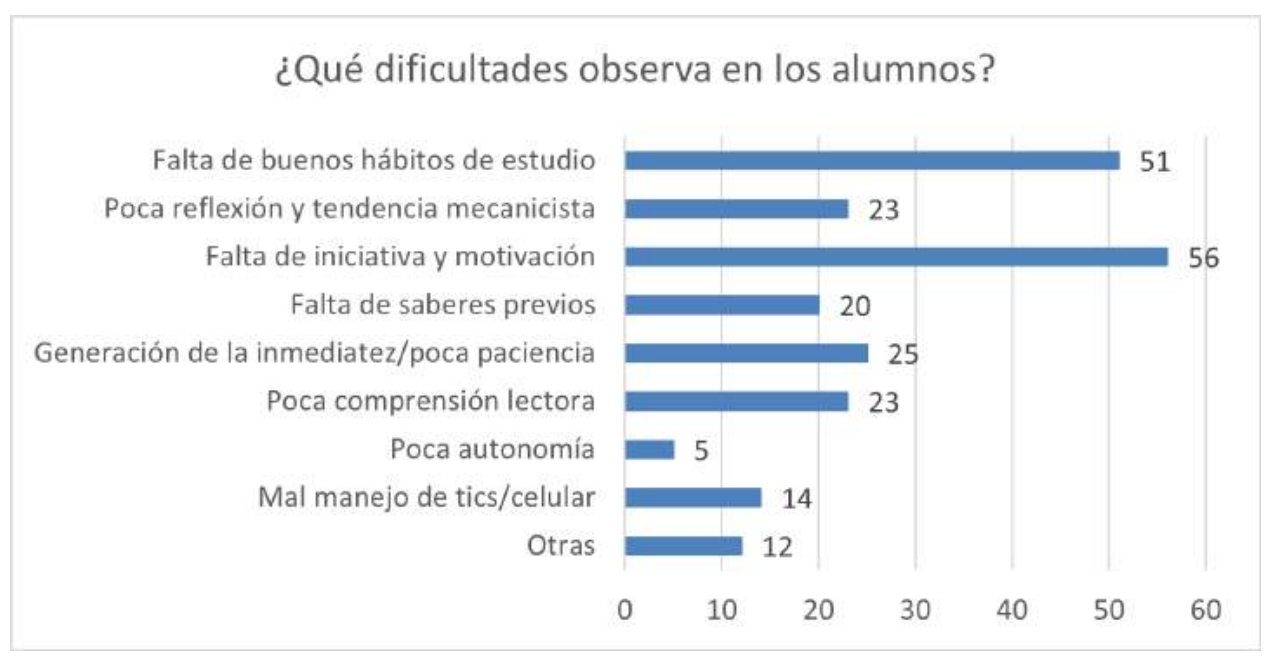

Figura 10: Resultados de la pregunta 1 de la segunda parte del cuestionario. Fuente: Elaboración propia.

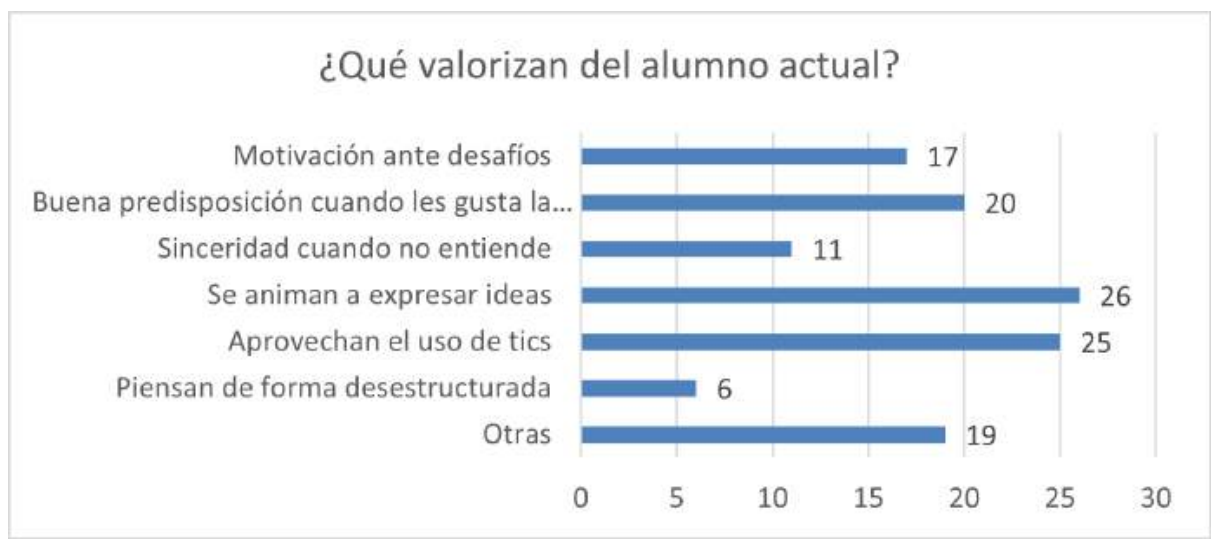

Figura 11: Resultados de la pregunta 2 de la segunda parte del cuestionario. Fuente: Elaboración propia.

Los encuestados tenían la posibilidad de agregar otras opciones entre los aspectos positivos que valorizaban de sus alumnos. Entre ellas, las respuestas más destacadas fueron la motivación observada en aquellos alumnos interesados en realizar carreras con contenidos matemáticos y la buena predisposición al trabajo grupal. Asimismo, mencionaron que los consideraban activos, espontáneos e inquietos, aunque tendientes a estudiar superficialmente antes que hacerlo de manera más profunda 
y fundamentada.

En la finalización del segundo bloque se dio lugar a un intercambio de opiniones entre los docentes invitados y anfitriones. En esta instancia se corroboró lo que mencionan los estudiantes cuando llegan a la Facultad respecto a temas no vistos en la escuela media, como es el tema de cónicas. Los docentes invitados, además, consultaron sobre cuáles temas sería conveniente profundizar en el colegio para que los alumnos lleguen con mejor preparación a la Facultad, llegándose a la conclusión de la importancia del buen manejo de operaciones básicas y algebraicas. Estas manifestaciones e inquietudes de los docentes constituyen disparadores para tratar de acercar a los estudiantes a los conocimientos o metodologías necesarios para la universidad. Según la UNSAM (2016, p.69), un camino es "preparar a los docentes de la escuela secundaria para que adecuen sus prácticas, a fin de ir preparando a los alumnos en el habitus universitario".

Los participantes de las Jornadas manifestaron que les parecía muy interesante la propuesta áulica en los cursos de matemática de la FI pero, a su vez, muchos de ellos consideraban inviable para desarrollar en sus escuelas. Estos docentes consideraban que no era factible por los tiempos de clase en la escuela secundaria y por la falta de recursos humanos (un solo docente para todo el curso). Por otro lado, se manifestaron agradecidos por haber sido convocados, lo cual les permitió conocer las aulas y la metodología utilizadas en las clases de la FI de manera de poder transmitir esa información a los estudiantes de sus cursos en el colegio secundario.

\section{Conclusiones}

En este trabajo relatamos una experiencia de articulación entre docentes de Matemática de dos niveles educativos: colegio secundario y universidad. La misma se desarrolló mediante tres jornadas destinadas a compartir la metodología de enseñanza que se utiliza en las clases de Matemática de la Facultad de Ingeniería. Estos encuentros permitieron continuar con las políticas de articulación con el nivel medio que se vienen realizando en esta Facultad.

Durante las jornadas se explicó cómo es la forma en que se dictan las clases en los cursos de Matemática en la institución, mostrando la utilidad de trabajar con modalidad de aula taller. Se realizaron intercambios entre los docentes de cada nivel que contribuyeron a estrechar lazos y conocer las realidades de cada ámbito educativo. También se logró caracterizar el rol del alumno desde la mirada de sus profesores con relación al estudio de la Matemática en el colegio secundario. Asimismo, se repensaron estrategias o acciones para que los estudiantes sean parte activa y protagónica del proceso de enseñanza y aprendizaje, adecuando su rol y el de los docentes a las nuevas demandas del contexto educativo. Conocer esta valorización de los alumnos próximos a ingresar en los estudios universitarios es importante para los docentes que los recibirán en la próxima etapa educativa. "Hay que revalorizar el rol del docente en la vida de los alumnos del nivel medio, dada la potencialidad que tiene para influir positivamente o no en la decisión de éstos sobre continuar los estudios en un nivel superior" (UNSAM, 2016, p.66).

Se considera que realizar estas jornadas de articulación enriqueció la actividad docente tanto de profesores invitados como de organizadores, dado que los acercan a distintas realidades experimentadas en las aulas. Estos intercambios, además, permitieron a los docentes anfitriones un mejor entendimiento de la realidad que viven los alumnos al momento de ingresar a la vida universitaria y a los docentes invitados conocer la institución, las aulas y la metodología donde se desarrollan las clases de matemática de los primeros años de las carreras de la FI. Esta experiencia les permite transmitir información a sus alumnos y prepararlos en el caso de que opten por una de estas carreras. En este sentido, a través de los resultados del cuestionario, pudo observarse que los docentes invitados consideran que a sus alumnos les resultaría difícil llevar a cabo actividades como la propuesta en la Jornada, que son típicas de la metodología que se utiliza en las clases de la FI. Se pueden destacar sus comentarios acerca de la dificultad que tienen los estudiantes para interpretar consignas y modelizar problemas, pero, a su vez, valorizando la motivación que muestran ante los desafíos. 
Por otra parte, se observó que los docentes de ambos ámbitos educativos presentan puntos en común sobre su rol en el desarrollo de las clases: momento en que se debe intervenir para dar una explicación y la realización de puestas en común. Así mismo, hubo coincidencias en las apreciaciones respecto a las dificultades y a las características a valorar de los alumnos que se encuentran en el tránsito entre los dos niveles.

Se espera poder continuar con estos encuentros de articulación orientando las temáticas a tratar en función de los aportes y sugerencias de los docentes participantes en estas jornadas y de las estrategias o actividades que se puedan implementar desde la Facultad de Ingeniería.

\section{Bibliografía}

[1] Aguerrondo, I. (2009). Niveles o ciclos. El reto de la articulación. Revista Internacional Magisterio, 38, 18-22.

[2] Altamirano, N., Di Domenicantonio, R., García, M., Langoni, L., y Trípoli, M. (2015). El Recorrido de Estudiantes Universitarios por un Proceso Diferente de Enseñanza y Aprendizaje de la Matemática. Comunicación presentada en el Encuentro Nacional sobre Enseñanza de Matemática en Carreras de Ingeniería (XIX EMCI Nacional y XI EMCI Internacional), San Nicolás, Buenos Aires.

[3] Ander-Egg, E. (1991). El taller. Una alternativa de renovación pedagógica. Editorial Magisterio del Río de La Plata. Buenos Aires, Argentina.

[4] Belinche, M.; Viñas, R.; Segul Giusti, C. y Viñas, M. (2014). Inclusión educativa. El ingreso a la universidad: ¿una posibilidad para todos? Memoria Académica del XVI Congreso de RedCom (celebrado en La Matanza, Argentina, del 14 al 16 de octubre de 2014), La Matanza, Buenos Aires. Recuperado de http://www.memoria.fahce.unlp.edu.ar/trab eventos/ev.13805/ev.13805.pdf

[5] Blanco Hernández, S. (2008). Reflexiones necesarias para una capacitación dirigida a docentes en la actual universidad cubana. Revista Pedagogía Universitaria 13 (4), 122-128.

[6] Camargo, M. (2004). Las necesidades de formación permanente del docente. Educación y educadores, $7,79-112$.

[7] Castelló, M., Liesa, E., y Monereo, C. (2012). El conocimiento estratégico durante el estudio de textos en la enseñanza secundaria. Revista Latinoamericana de Psicología, 44 (2), $125-141$.

[8] De Moreno, B. (2015). Articulación: algunas reflexiones en el contexto de la formación docente. Programa Nacional de Formación Permanente de la Pcia. de Buenos Aires.

[9] Díaz Herrera, C. (2018). Investigación cualitativa y análisis de contenido temático. Orientación intelectual de revista Universum. Revista general de Información y Documentación 28 (1), 119-142.

[10] Dirección de Currícula, Gobierno de la Ciudad Autónoma de Buenos Aires, (2000). Diseño Curricular para la Educación Inicial. ISBN 987-9327-61-6.

[11] Espinosa, J. (2012). Organización de la Capacitación. En ESPINOSA, J. (ed.) Capacitación y Desarrollo de Personal (p. 40). Trillas, México.

[12] García, M. (2017). Propuesta de aula taller en el Curso de Nivelación para el ingreso a Ingeniería. Trabajo final integrador. Universidad Nacional de La Plata. Facultad de Humanidades y Ciencias de la Educación. En Memoria Académica. Disponible en: http://www. memoria. fahce. unlp.edu.ar/tesis/te.1532/te.1532.pdf 
[13] González A., Esnaola F. y Martín M. (2012). Propuestas educativas mediadas por tecnologías digitales. ISBN nº 978-950-34-0937-4 Editorial: EUNLP.

[14] Luchetti, E. (2005). Articulación. Un pasaje exitoso entre distintos niveles de enseñanza. Editorial Bonum, CABA. Argentina.

[15] Rodríguez Vite, H. (2017). Importancia de la formación de los docentes en las instituciones educativas. Ciencia Huasteca Boletín Científico De La Escuela Superior De Huejutla, 5 (9). Recuperado de https://doi.org/10.29057/esh.v5i9.2219.

[16] Ruiz Olabuénaga, J. I. (2012). Metodología de la investigación cualitativa. Universidad de Deusto. Bilbao, España.

[17] Secretaría Académica de la Universidad Nacional de General San Martín (UNSAM) (2016). Formar y Formarse en la UNSAM, Articulación Universidad - Escuelas Secundarias. ISSN 2545-6938.

[18] Tauber, F. (2010). Buscan articular la enseñanza media con la universitaria para evitar la deserción. Diario Diagonales, 01/06/2010. Recuperado de http://www. infonews . com/ nota. php?id=92999\&bienvenido=1. Accedido el 31 de agosto de 2012.

[19] Vargas Larrea, J., Fernández Busse, M., Ferrari, F. A., \& Cordero, M. C. (2017, Mayo). La extensión universitaria en procesos de articulación universidad-escuela media. En IV Jornadas de Investigación, Transferencia y Extensión de la Facultad de Ingeniería (La Plata, 2017).

[20] Walker, V.S. (2012). El tránsito de los estudiantes por la universidad. Edumet.net Enciclopedia virtual. Recuperado de http: //www. eumed. net/libros - gratis/ciencia/2012/10/. Accedido el 19 de nov. de 2019. 


\section{A. Anexos}

\section{A.1. Anexo 1}

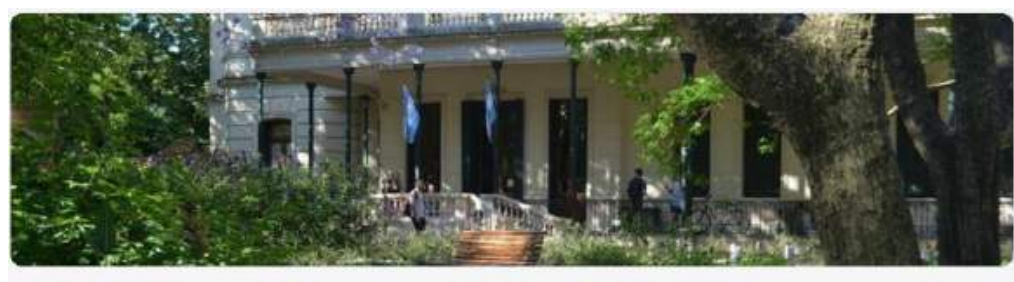

Jornada de Articulación en la Facultad de Ingeniería UNLP

Fecha: Martes 04 de Septiembre

Horario: 09.00 a $12: 00$

Lugar: Edif Central -Facultad de Ingeniería (1 y 47)

Aula: German Fernández ( $1^{\circ}$ piso del Edificio Central)

Por cualquier consulta escribir mail a: matepifi@gmail.com

\section{Daros personales del Docente que asistirá}

Apellido *

Tu respuesta

Datos del Colegio al cual representa

Nombre *
Tu respuesta
Mail del docente *
Tu respuesta
Tu respuesta
¿Cómo te enteraste de esta jornada?
Plataforma Moodle
Director de su colegio
Anuncio en la página web de la Facultad
otros:

Colegio *

Tu respuesta

Localidad

Tu respuesta

Localidad *

Tu respuesta

Tipo de colegio

Estatal

$\square$ Privado

$\square$ Universidad

$\square$ Técnico

$\square$ Otros:

Figura 12: Formulario de inscripción a las Jornadas de articulación entre docentes de Matemática de Colegios Secundarios y de Universidad. Fuente: Elaboración propia.

Jornada de articulación entre docentes de Matemática de Colegios Secundarios y de Universidad: una experiencia en la Facultad de Ingeniería de la Universidad Nacional de La Plata, Argentina. Di Domenicantonio, R., García, M., Langoni, L.

Derechos Reservados @ 2021 Revista digital Matemática, Educación e Internet (https://tecdigital.tec.ac.cr/revistamatematica/) 


\section{A.2. Anexo 2}

\section{Cuestionario:}

Institución Secundaria de la que proviene:
a) Pública.
c) Colegio de la Universidad.
b) Privada
d) Técnica.

Años en los que desempeña su tarea docente:
a) $1^{\circ}-2^{\circ}-3$
b) $4^{0}-5^{0}-6^{0}$
c) Ambos.

1. ¿En qué momento considera que se puede presentar al alumno esta actividad? Seleccione solo una opción y explique por qué.
a) Antes de dar una explicación del tema elipse.
c) Como trabajo práctico para cierre del tema.
b) Durante la explicación del tema.
d) Otra.

Explique:

2. ¿Piensa usted que los alumnos pueden trabajar en grupo con una actividad de este estilo?
a) $\mathrm{Si}$
b) No
c) Depende

Explique:

3. ¿Considera que los alumnos pueden resolver totalmente la actividad sin inconvenientes?
1. $\mathrm{Si}$
2. No
3. Depende

Explique:

4. Si no estuviese pautado el enunciado, ¿cree que los alumnos hubiesen modelizado matemáticamente esta situación real?
a) $\mathrm{Si}$
b) No
c) Depende

Explique:

5. ¿Qué inconvenientes piensa Ud. que se le presentan a los alumnos al responder esta actividad?
a) Interpretación del problema.
b) Encontrar la ecuación -Modelización del problema.
f) Falta de conocimientos previos o de relacionarlos con ellos.
c) No conocer el concepto de elipse.
d) Resolver analíticamente el problema.
e) Terminología utilizada.
g) Representación gráfica.
h) Resolución no mecánica.
i) Otra.

Explique:

6. ¿En qué instancia/s considera oportuno que el docente intervenga de alguna manera durante el trabajo de los alumnos?
a) Cuando el alumno lo requiera/necesite.
d) Al inicio.
b) En todo momento/permanentemente.
e) Otra.
c) En el debate/discusión/cierre.

Explique:

7. ¿Cómo imagina un cierre de esta actividad en su aula?
a) Mediante una puesta en común.
d) Formalizando los conceptos.
b) Agregando preguntas a la actividad para enriquecer la
e) Usando software matemático para graficar. situación.
c) Planteando situaciones similares donde apliquen el tema
f) Con grupos de alumnos pasando al pizarrón.
g) Otra. cónicas.

Explique:

Figura 13: Cuestionario sobre los datos docentes y la actividad realizada. Fuente: Elaboración propia.

Jornada de articulación entre docentes de Matemática de Colegios Secundarios y de Universidad: una experiencia en la Facultad de Ingeniería de la Universidad Nacional de La Plata, Argentina. Di Domenicantonio, R., García, M., Langoni, L.

Derechos Reservados @ 2021 Revista digital Matemática, Educación e Internet (https://tecdigital.tec.ac.cr/revistamatematica/) 


\section{A.3. Anexo 3}

\section{$\underline{\text { Respecto a su experiencia docente con alumnos del colegio secundario: }}$}

1. ¿Qué dificultades observa en los alumnos?
a) Falta de buenos hábitos de estudio.
f) Poca comprensión lectora.
b) Poca reflexión y tendencia mecanicista.
g) Poca autonomía.
c) Falta de iniciativa y motivación/predisposición.
h) Mal manejo de tics/celular.
d) Falta de saberes previos.
i) Otra
e) Buscan la inmediatez/poca paciencia.

Explique:

2. ¿Qué valoriza del alumno actual?
a) Motivación ante desafíos.
e) Aprovechan el uso de tics.
b) Buena predisposición cuando les gusta la temática.
f) Piensan de forma desestructurada.
c) Sinceridad cuando no entiende.
g) Otra.
d) Se animan a expresar ideas.

Explique:

Figura 14: Cuestionario sobre la experiencia docente. Fuente: Elaboración propia.

\section{A.4. Anexo 4}

Las guías de clase teórico prácticas de las dos primeras materias de Matemática que cursan los alumnos de la FI, Matemática PI y Matemática A, se pueden encontrar en:

Matemática PI: https ://www. ing. unlp.edu.ar/ingreso

Matemática A: https://WWw.ing.unlp.edu.ar/catedras/F0301/

\section{Foro de consultas. Capitulo 2}

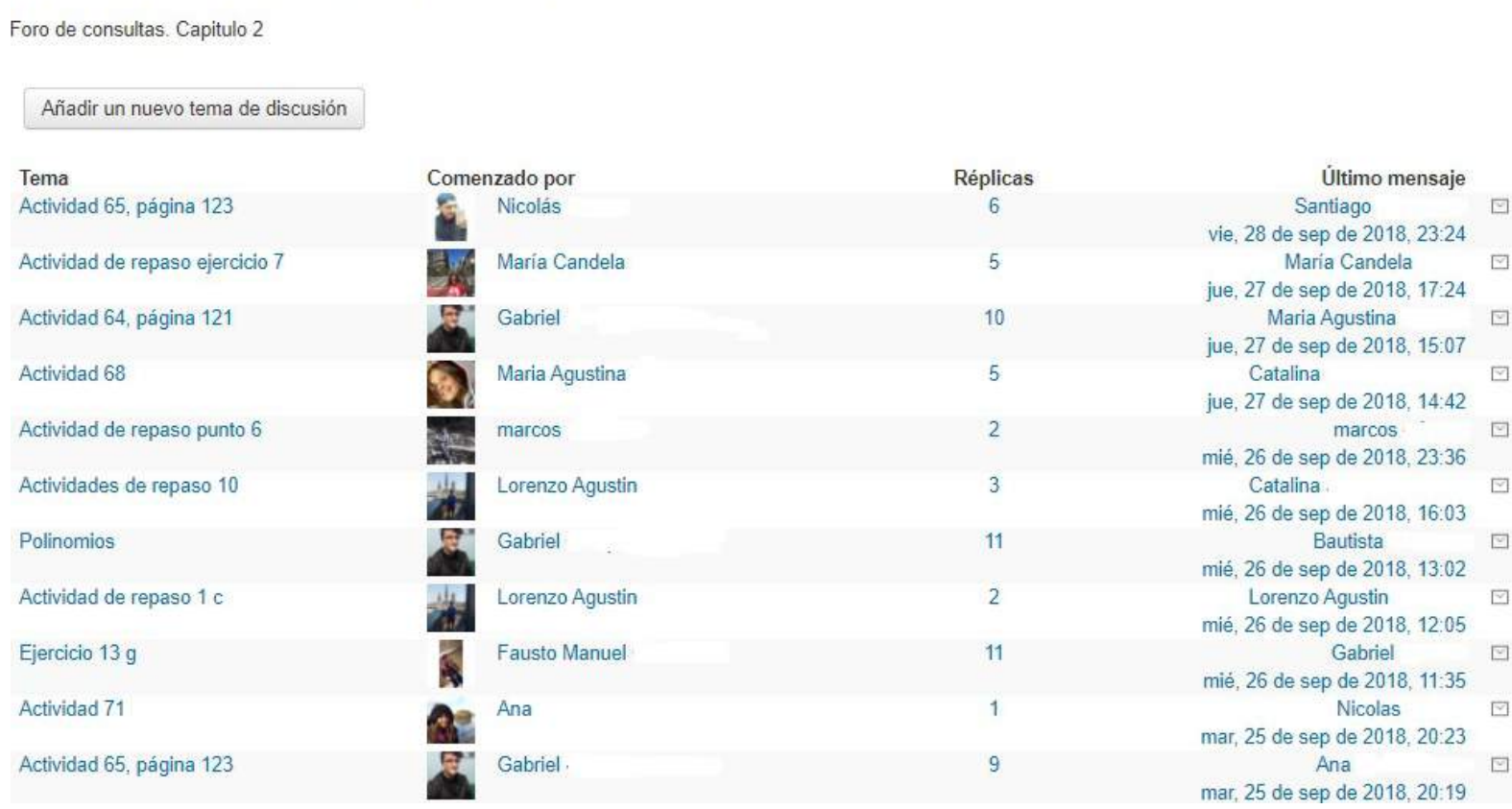

Figura 15: Ejemplo de la interacción de alumnos y docentes en un foro de preguntas y respuestas organizado por capítulo y por ejercicio. 
Re: Ayuda 40) 41) 42

de Nicolás miércoles, 17 de octubre de 2018, 10:15

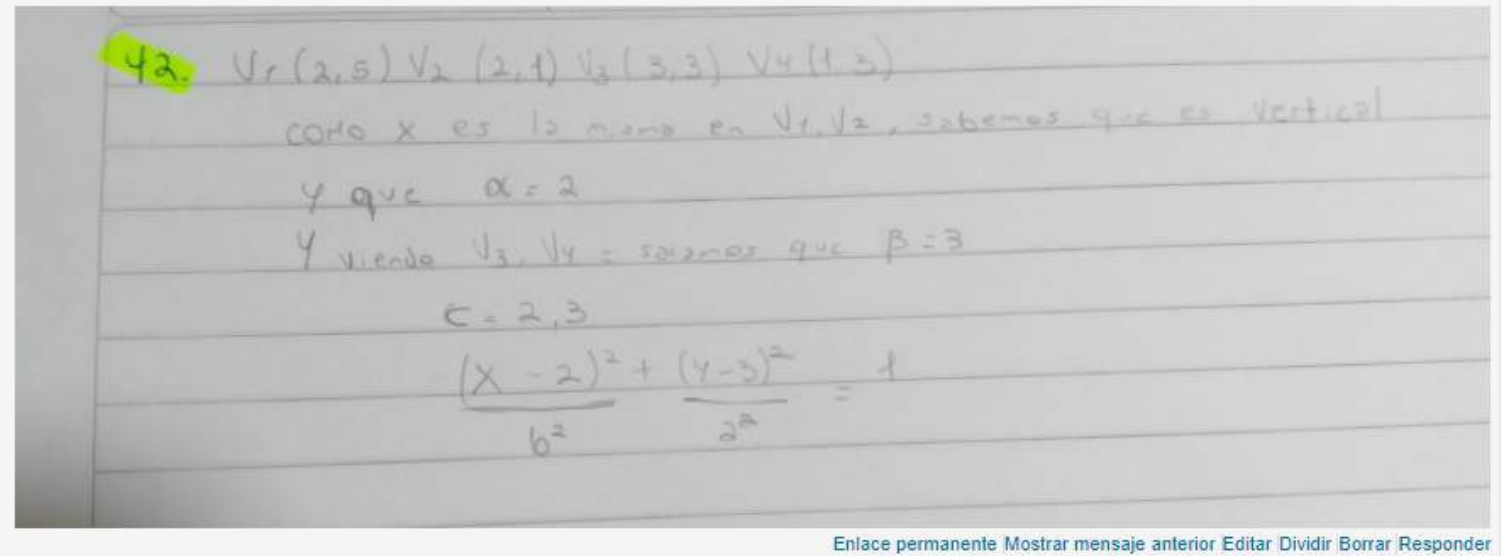

Re: Ayuda 40) 41) 42)

de Gabriel

Hola Nicolás. Cómo estás?

En primer lugar, tenés un error con el centro de de la elipse. El enunciado dice que tiene centro en 3 y -2 . Entonces alfa $=3$ y beta $=-2$.

Figura 16: Ejemplo de las intervenciones de alumnos en el foro.

\section{Mabel}

ha subido un archivo.

Administrador $\cdot 22$ de marzo de $2019 \cdot 8$

Les dejamos unos ejercicios de derivadas a modo de autoevaluación. Resuélvanlos y en un par de días les subimos la resolución. Buen finde!!

- DOCUMENTO

w Autoevaluación 1.docx

008 Visto por 36

d3 Me gusta $\square$ Comentar

Figura 17: Ejemplo de los distintos usos dados a los grupos de Facebook.

\section{A.5. Anexo 5}

Resultados cuantitativos de una encuesta que se hizo a los alumnos respecto a su percepción sobre la forma de trabajar en las aulas de Matemática de la FI. Estos resultados se mostraron en la presentación realizada durante las Jornadas. La encuesta es de elaboración propia y se realizó en el primer semestre de 2019 a 308 alumnos de las dos primeras materias de matemática de la FI, Matemática para Ingeniería (165 estudiantes encuestados) y Matemática A (143 estudiantes encuestados). Se realizó cuando los estudiantes ya habían visto todo el contenido de la asignatura, pero no habían terminado la totalidad de las evaluaciones del curso. En las dos primeras preguntas los encuestados sólo podían elegir una de las opciones mientras que en la tercera podían seleccionar más de una opción. 


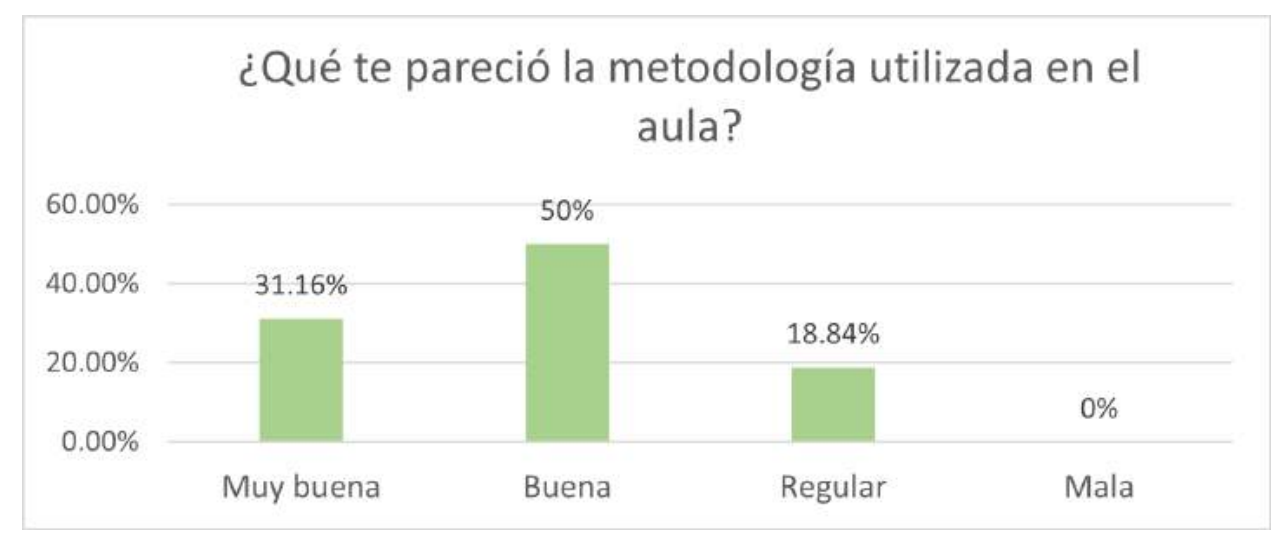

Figura 18: Valoración de los alumnos sobre la metodología utilizada en el aula.

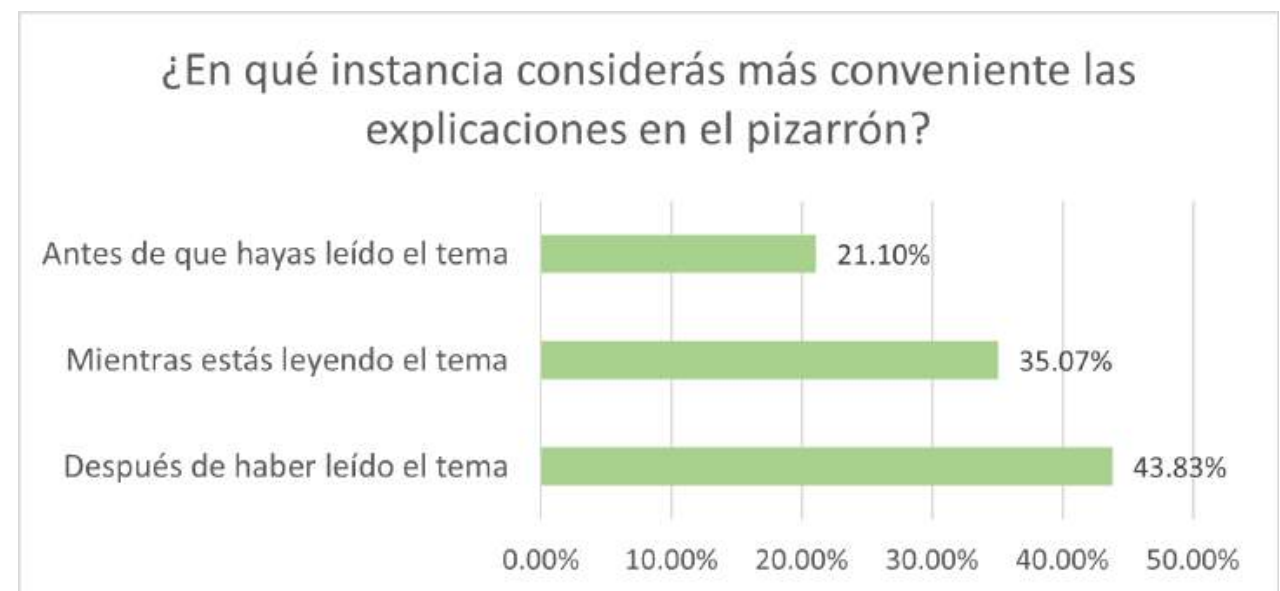

Figura 19: Preferencia de los alumnos respecto al momento del uso del pizarrón.

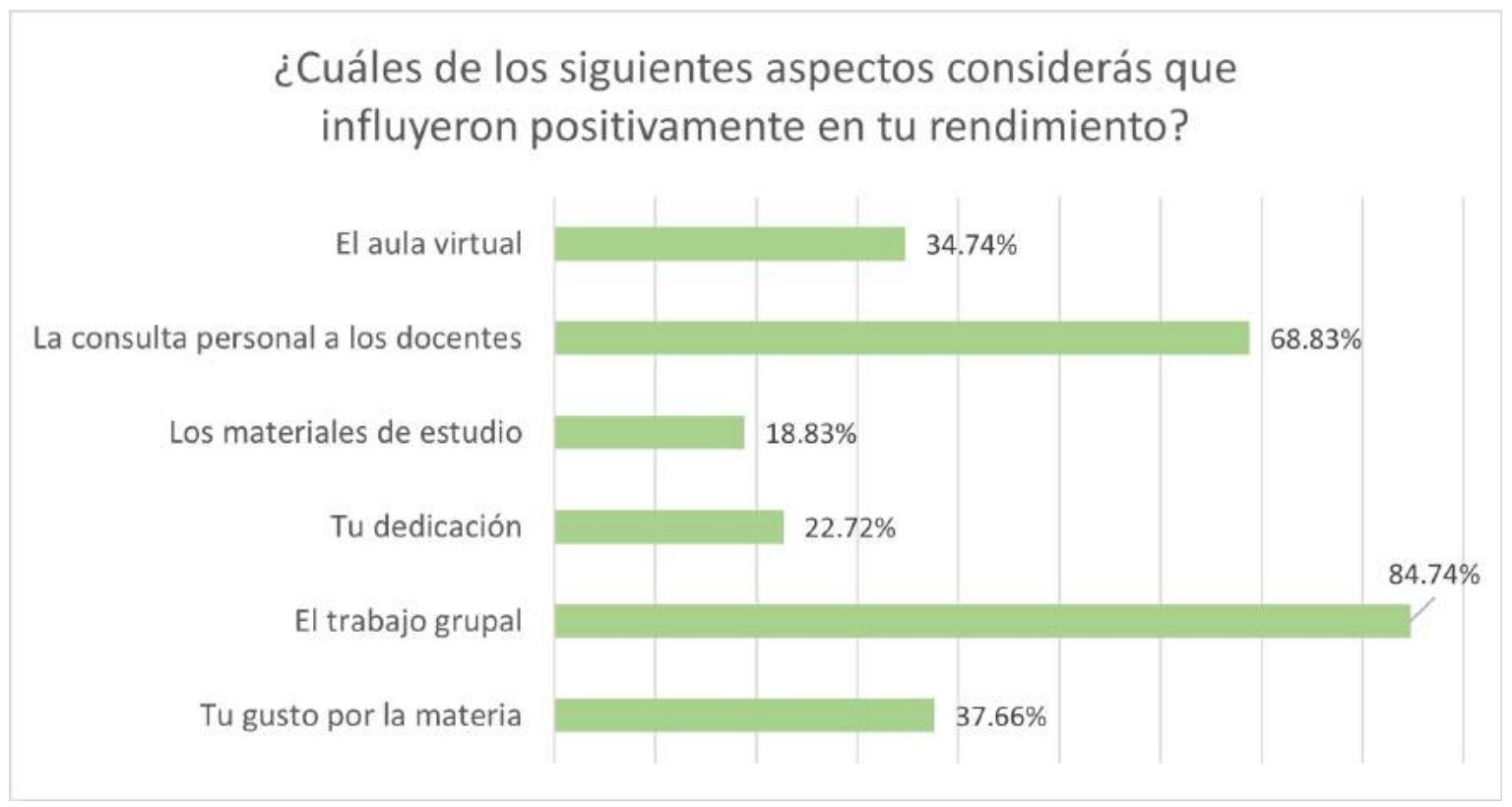

Figura 20: Opinión de los alumnos respecto a los factores que influyeron positivamente en su rendimiento.

Jornada de articulación entre docentes de Matemática de Colegios Secundarios y de Universidad: una experiencia en la Facultad de Ingeniería de la Universidad Nacional de La Plata, Argentina. Di Domenicantonio, R., García, M., Langoni, L.

Derechos Reservados @ 2021 Revista digital Matemática, Educación e Internet (https://tecdigital.tec.ac.cr/revistamatematica/) 